\title{
BMJ Open Healthcare Options for People Experiencing Depression (HOPE*D): the development and pilot testing of an encounter-based decision aid for use in primary care
}

\author{
Paul J Barr, ${ }^{1}$ Rachel C Forcino, ${ }^{1}$ Michelle D Dannenberg, ${ }^{1}$ Manish Mishra, ${ }^{1,2}$ \\ Erick Turner, ${ }^{3,4}$ Yaara Zisman-Ilani, ${ }^{5}$ Jim Matthews, ${ }^{6}$ Michelle Hinn, ${ }^{7}$ \\ Martha Bruce, ${ }^{1,8}$ Glyn Elwyn ${ }^{1}$
}

To cite: Barr PJ, Forcino RC Dannenberg MD, et al. Healthcare Options for People Experiencing Depression (HOPE*D): the development and pilot testing of an encounterbased decision aid for use in primary care. BMJ Open 2019;9:e025375. doi:10.1136/ bmjopen-2018-025375

- Prepublication history and additional material for this paper are available online. To view these files, please visit the journal online (http://dx.doi org/10.1136/bmjopen-2018025375).

Received 12 July 2018 Revised 23 January 2019 Accepted 5 February 2019

Check for updates

(C) Author(s) (or their employer(s)) 2019. Re-use permitted under CC BY-NC. No commercial re-use. See rights and permissions. Published by BMJ.

For numbered affiliations see end of article.

Correspondence to

Dr Paul J Barr;

Paul.J.Barr@dartmouth.edu

\section{ABSTRACT}

Objective To develop and pilot an encounter-based decision aid (eDA) for people with depression for use in primary care.

Design We developed an eDA for depression through cognitive interviews and pilot tested it using a one-group pretest, post-test design in primary care. Feasibility, fidelity of eDA use and acceptability were assessed using recruitment rates and semistructured interviews with patients, medical assistants and clinicians. Treatment choice and shared decision-making (SDM) were also assessed.

Setting Interviews with adult patients and the public were conducted in a mall and library in Grafton County, New Hampshire, while clinician interviews took place by phone or at the clinician's office. Pilot testing occurred in a New Hampshire primary care practice.

Participants Cognitive interviews were conducted with adults, $\geq 18$ years, who could read English from the following stakeholder groups: history of depression, the public and clinicians. Patients with a Patient Health Questionnaire- 9 score of $\geq 5$ were recruited for piloting.

Results Three stages of cognitive interviews were conducted $(n=28)$. Changes to eDA included moving the combination therapy information and access to treatment information, adding colour, modifying pictograms and editing the talk-therapy description. Clinician concerns about patient health literacy were not reflected in patient interviews. Of 59 patients who reviewed study information, 56 were eligible and agreed to participate in pilot testing; however, only 29 could be reached for follow-up. The eDA was widely accepted, though clinicians did not always use it as intended. We found no impact of eDA use on SDM, though patients chose a wider range of treatment options.

Conclusions We demonstrated the feasibility of the use of an eDA for depression in primary care that was widely accepted. Further research is needed to improve the fidelity with which the eDA is used and to assess its impact on SDM and related health outcomes.
Strengths and limitations of this study

- Systematic development of an encounter-based decision aid (eDA) with a community-based focus and broad engagement of key stakeholders both in the community and clinic throughout development.

- Participants reflective of different education levels, indicating increased accessibility of the eDA for patients of different health literacy levels.

- eDA was considered comprehensive, helpful and was widely accepted.

- High attrition of $53 \%$ (30/59) of patients at follow-up.

- Clinicians accepted the eDA but did not regularly use it as intended with patients.

\section{BACKGROUND}

Shared decision-making (SDM) is a process by which patients and clinicians make decisions together accounting for patient preferences in light of the best available evidence for treatment options and is the recommended approach making decisions in depression care. ${ }^{1}$ SDM results in treatment decisions aligned with patient preferences, leading to improvements in patient satisfaction, treatment completion and clinical outcomes. ${ }^{2}$ For individuals with depression, alignment of preferences with treatment can also result in greater treatment initiation accelerate symptom improvement. ${ }^{3-5}$ Despite SDM being recommended for the management of depression in primary care,${ }^{1}$ patients continue to report low levels in practice ${ }^{6-9}$ Compounding this issue is that depression screening is routine in the US primary care settings ${ }^{10}{ }^{11}$ completed via a Patient Health Questionnaire (PHQ-9) survey in a waiting room, allowing little time 
for decision support should a patient present with symptoms of depression.

Decision aids (DAs) are tools used to provide balanced information on treatments, clarify patient values and facilitate patient engagement in decision-making. In a recent systematic review of DAs in health settings in general ${ }^{12}$ and in mental health settings specifically, ${ }^{13}$ DAs were found to increase knowledge, improve alignment of treatment with patient preferences, increase patient satisfaction and reduce decisional conflict. In addition, DAs designed for use during the clinic visit, encounter-based DAs (eDAs), are associated with increased SDM. ${ }^{12}$ Despite these benefits, only one depression DA for use in primary care has been developed and tested in the US context, and it focuses only on antidepressants. ${ }^{8}$

The aim of this study was to address the lack of a comprehensive DA for depression for use in primary care, where a reported $73.3 \%$ of depression treatment is managed. ${ }^{14}$ In this paper, we report the development and pilot testing of the eDA for depression. We modelled the eDA for depression on the Option Grid DAs, which provide a single page summary of options for a health issue and are organised in a tabular format with frequently asked patient questions (FAQs) forming the rows and treatment options forming the columns. ${ }^{15} 16$ We chose to model the eDA for depression on Option Grid DAs as they are specifically designed to fit within clinic workflows. Our mixed-methods project consisted of two parts: (1) eDA development and (2) a pilot study to establish the feasibility of using the eDA for depression in primary care.

\section{METHODS}

\section{Patient involvement}

Our patient and caregiver partners attended weekly meetings with the research team, where they contributed to all aspects of the study, from designing the study to manuscript preparation. While they were not directly recruiting participants for this study, they helped to create all of the recruitment materials, as well as the semistructured interview guide. Patient partners are also co-authors on this article (JM and $\mathrm{MH}$ ). Our research findings will be shared with the public through Mental Health America and with our clinic partners (Dartmouth-Hitchcock).

\section{Part 1. eDA development}

\section{Evidence synthesis for DA}

FAQs for the eDA were based on data from a US survey of individuals with depression and clinicians. ${ }^{9}$ Three firstline approaches for managing depression were identified from guidelines, including watchful waiting, talk therapy (cognitive behavioural therapy and problem solving therapy) and medication (selective serotonin reuptake inhibitors). The content of the eDA for depression was informed by guidelines, other decision support tools and a systematic review of the efficacy of antidepressants, corrected for publication bias (see online supplementary file 1). Local and national experts in the field of depression provided informal feedback used to refine the DA for use in cognitive interviews (figure 1).

\section{Content refinement}

\section{Cognitive interviews}

Cognitive interviews are an integral part of measure and intervention development ${ }^{17}$ that can be used to assess comprehension and understanding of the target audience. We sought a minimum of six participants from each group at each stage to reach saturation of themes. ${ }^{18}$

\section{Participants and settings}

We conducted cognitive interviews with adults, aged 18 years or older, who were able to read English. We recruited and consented participants from three stakeholder groups. (1) Patients: Individuals who have been treated or are currently receiving treatment for depression. We invited respondents from our national survey of individuals with a self-reported history of depression. ${ }^{9}$ Interviews took place by phone. (2) General public: Members of the general public, with no history of depression, provided the perspective of a new patient. A member of the research team approached (MD or $\mathrm{PB}$ ) individuals for an in-person interview in a shopping centre and a community library in Grafton County, New Hampshire. (3) Clinicians: Clinicians from the Dartmouth CO-OP Practice-based Research Network, a group of approximately 100 clinics across New England, who worked in primary care, were invited by email to participate in an interview. Interviews were conducted by $\mathrm{MD}$ and took place by phone or in-person at the clinician's office. We purposefully choose to focus on primary care clinicians, rather than specialists (eg, psychiatrists) as first-line treatment for depression is typically managed in primary care. ${ }^{14}$ All participants were offered a US $\$ 10$ gift card for participation in the study.

\section{Data collection}

We conducted a series of semistructured cognitive interviews using prespecified probes (online supplementary file 2). In their own words, participants were asked to describe the assumed purpose of the eDA for depression, when it should be introduced to patients, and whether any important information was missing. Comprehension was also assessed through questions about the content of the DA. We conducted three rounds of cognitive interviews. In rounds one and two, we concentrated on patients and the general public. In round three, we focused on clinicians that worked in primary care. The interviews were audio recorded and transcribed. Each interview lasted between 15 and $30 \mathrm{~min}$.

\section{Data analysis}

Conventional content analysis was undertaken by two members of the research team (MD and $\mathrm{PB}$ ) who independently completed double coding of all interviews. ${ }^{19}$ After initial coding, a selection of transcripts, coders met to agree on a codebook to apply to the remaining transcripts. Themes were then compared within and across 
Below are some ways of treating depression. Most people will recover from depression, however the first treatment may not work and depression may reoccur. It is okay to revisit a treatment decision at anytime.

\begin{tabular}{|c|c|c|c|}
\hline $\begin{array}{l}\text { Frequently asked } \\
\text { questions }\end{array}$ & Watchful waiting & Medication & Talk therapy \\
\hline $\begin{array}{l}\text { How does this } \\
\text { work? }\end{array}$ & $\begin{array}{l}\text { This means no active } \\
\text { treatment; you may visit } \\
\text { your clinician more } \\
\text { frequently to monitor your } \\
\text { symptoms, compare } \\
\text { options and discuss your } \\
\text { lifestyle, current support } \\
\text { and coping strategies. }\end{array}$ & $\begin{array}{l}\text { Selective Serotonin Reuptake Inhibitors } \\
\text { (SSRIs) are medications that address } \\
\text { symptoms by affecting your brain } \\
\text { chemistry. These pills are usually taken } \\
\text { once a day. }\end{array}$ & $\begin{array}{l}\text { Therapy addresses symptoms by } \\
\text { helping you solve problems and clarify } \\
\text { your thoughts. This is typically a } \\
\text { weekly one-hour session. } \\
\text { In person: Working with a therapist. } \\
\text { On a computer: Using a program on } \\
\text { your own or with support from your } \\
\text { clinician by email or phone. }\end{array}$ \\
\hline Will this work? & $\begin{array}{l}23 \text { out of } 100 \text { people } \\
\text { recover in } 3 \text { months by } \\
\text { visiting a clinician without } \\
\text { receiving an active } \\
\text { treatment. } 53 \text { out of } 100 \\
\text { people recover in a year } \\
\text { without receiving an active } \\
\text { treatment. }\end{array}$ & $\begin{array}{l}\text { In addition to the } 23 \text { people who } \\
\text { recover without treatment another } 17 \\
\text { out of } 100 \text { people recover in } 1 \text { month } \\
\text { by using SSRI medication. Treatment } \\
\text { usually lasts } 6 \text { to } 12 \text { months. You should } \\
\text { talk to your clinician if you are thinking } \\
\text { about stopping medication. }\end{array}$ & $\begin{array}{l}\text { हิ } \\
\text { In addition to the } 23 \text { people who } \\
\text { recover without treatment another } 14 \\
\text { out of } 100 \text { people recover in } 2 \text { months } \\
\text { by using talk therapy. Treatment } \\
\text { usually lasts } 8 \text { to } 10 \text { weeks, but can } \\
\text { last longer. computer programs are } \\
\text { more effective with regular clinic } \\
\text { check-ins. }\end{array}$ \\
\hline $\begin{array}{l}\text { What are the side } \\
\text { effects of this? }\end{array}$ & $\begin{array}{l}\text { Your symptoms may } \\
\text { continue or get worse. } \\
\text { Roughly } 25 \text { in } 100 \text { people } \\
\text { will see their symptoms } \\
\text { get worse. }\end{array}$ & $\begin{array}{l}\text { Side effects like nausea, diarrhea, and } \\
\text { drowsiness each affect up to } 17 \text { in } 100 . \\
\text { Sexual problems affect up to } 13 \text { in } 100 \text {. } \\
\text { Sweating, shaking, difficulty sleeping, } \\
\text { and dry mouth are less common. }\end{array}$ & $\begin{array}{l}\text { Talk therapy can cause discomfort, } \\
\text { anxiety, and/or stress. }\end{array}$ \\
\hline $\begin{array}{l}\text { How much does } \\
\text { this cost? }\end{array}$ & $\begin{array}{l}\text { Cost will depend on the } \\
\text { type and frequency of } \\
\text { visits to your clinician. } \\
\text { Work with your clinician, } \\
\text { employer, and/or } \\
\text { insurance company to } \\
\text { determine your costs. }\end{array}$ & $\begin{array}{l}\text { Without insurance, prices vary by } \\
\text { pharmacy. In general fluoxetine, } \\
\text { citalopram, and paroxetine cost less } \\
\text { than } \$ 5 \text { for a } 30 \text {-day supply. Sertraline } \\
\text { usually costs less than } \$ 40 \text { and } \\
\text { escitalopram less than } \$ 130 \text { for a } 30- \\
\text { day supply. With insurance, prices vary } \\
\text { by plans. }\end{array}$ & $\begin{array}{l}\text { In person: Prices will vary. Work with } \\
\text { your clinician, employer, or insurance } \\
\text { company to determine your costs. } \\
\text { On a computer: Evidence based } \\
\text { programs include "MoodGym" and } \\
\text { "Beating the Blues". Access to } \\
\text { MoodGym is free at } \\
\text { www.moodgym.anu.edu.au. }\end{array}$ \\
\hline $\begin{array}{l}\text { Is there anything } \\
\text { else I can do? }\end{array}$ & \multicolumn{3}{|c|}{$\begin{array}{l}\text { In addition to the } 23 \text { people who recover without treatment, another } 26 \text { in } 100 \\
\text { people recover with a combination of SSRIs and talk therapy. Exercise, healthy } \\
\text { eating, and visiting with friends can also reduce symptoms. }\end{array}$} \\
\hline
\end{tabular}

Figure 1 eDA for depression (V.1) for cognitive interviews. eDA, encounter-based decision aid.

groups (patients, general public and clinicians). Theme and coding matrices were used to organise the data and identify commonly occurring misunderstandings, concerns and comments about the eDA. Refinements were made following each stage of interviews, continuing until no new issues were identified.

\section{Part 2. eDA pilot testing}

The primary aim of the second part of the study was to assess the acceptability of the eDA for depression, explore the feasibility of using the tool in a primary care practice. We also conducted a formative examination of the impact of the eDA on SDM; however, no formal power estimates were planned. This was examined through a one-group pretest, post-test design with independent patient samples, and with the eDA for depression introduced after the initial pretest period.

\section{Setting and participants}

This study was conducted in a primary care practice of an academic teaching hospital in New Hampshire, beginning in August 2015 for a data collection period of 26 weeks. Patients visiting one of four general internal medicine clinicians were eligible for inclusion.

Individuals 18 years of age or older and able to read and write in English, who scored $\geq 5$ on the routinely administered PHQ-9 (a score aligned with existing clinic protocols for depression screening) were eligible for inclusion. Patients taking medication for depression that was managed by a clinician other than their 
primary care clinician and individuals who screened positive for suicidal ideation were not eligible for inclusion and continued with routine clinical care.

\section{Intervention and training}

Following pretest data collection, medical assistants (MAs) and clinicians received group training from the same two researchers on the study protocol and use of an eDA by two members of the research team (PB and $\mathrm{MD}$ ). The 60-min seminar was based on the 12 domains of behaviour change.$^{20}$ Training involved an explanation of the purpose of the eDA, sources for the evidence informing eDA content and how to use the eDA (online supplementary file 3). Clinicians were encouraged to use it with patients while making depression treatment decisions. Videos demonstrating how to use an eDA and how not to use an eDA were also provided (available on request). Patients were to be given the eDA and encouraged to review it prior to the clinician entering the exam room. Patients were also to be asked to use the eDA with their clinician if they discussed treatment for depression.

\section{Study procedure}

All patients visiting a participating clinician completed a PHQ-9 survey in the waiting room. In the exam room, patients who scored $\geq 5$ on the PHQ-9 received an electronic tablet from the MAs with study information, eligibility questions and contact information. The survey was programmed using Qualtrics, a survey hosting program. During the pretest period, patients received usual care. During the post-test period, patients were given the eDA to review in addition to usual care. Patients were encouraged to use the tool if a discussion of depression treatment occurred with the clinician. Clinicians also kept a copy of the eDA in their office to be used with patients. All patients were followed-up by telephone within 2 days of the clinic visit. During this call, the patient answered questions about his or her care experience. On completion, patients received a US $\$ 10$ Amazon gift code or a US $\$ 10$ grocery store gift card.

\section{Data collection}

During the follow-up telephone call with patients, depression treatment history and sociodemographics were assessed by a member of the research team (MD). We recorded treatment chosen and evaluated SDM experienced using CollaboRATE, ${ }^{21} 22$ a 3-item measure, and the 9-item shared decision making questionnaire (SDMQ-9), ${ }^{23}$ a 9-item measure. We examined knowledge and interpretation of eDA information in intervention patients through questions about treatment availability, effectiveness and risks. Intervention patients who used the eDA were asked about the perceived pros and cons of the tool. The feasibility of implementing the eDA for depression was assessed in two ways: (1) by calculating the proportion of eligible patients who agreed to take part and (2) through semistructured debrief interviews by a member of the research team (PJB) with participating clinicians and MAs to assess their experience and use of the eDA.

\section{Data analysis}

We conducted a thematic analysis of interviews conducted with clinicians and MAs. While a formal power calculation was not conducted, we compared SDM levels preintroduction and postintroduction of the eDA for depression. A one-sided Fisher's exact test compared the proportions of patients who gave a CollaboRATE top score, and a Mann-Whitney U/Wilcoxon rank-sum test was used to compare the SDM-Q-9 scores. Given the pilot nature of the project, we did not attempt to substitute missing data. Patients who reported discussing depression treatments during their consultations at the follow-up telephone call were included in the analysis. All analyses were conducted in Stata V.13.

\section{RESULTS}

\section{Part 1. eDA development}

Stages 1 and 2: patients and the general public

A total of 28 participants were interviewed across the two stages, including 12 patients and 16 members of the general public (table 1). Majorities of participants were female $(n=20)$ and held paid employment $(n=20)$. Educational attainment ranged from high school $(n=10)$ to bachelors and postgraduate completion $(n=9)$.

\section{Overall impression}

Overall, participants in stages 1 and 2 felt the eDA for depression was comprehensive, easy to use and understand, and would be helpful to someone making a depression treatment decision. Participants correctly indicated that the purpose of the DA is to present different treatment options for depression and were able to broadly summarise the options. Participants felt the best time to receive the DA would be during a visit with their clinician $(n=8)$, either before or during the visit $(n=6)$ or before the visit $(n=3)$. Participant quotes illustrating key themes are listed in table 2. Changes by interview stage are described below and highlighted in table 3 .

\section{Suggested changes}

After the first stage of interviews, we changed the pictogram used to represent treatment effectiveness from dots to 'people' as the dots were found to be confusing. We also added bright colours to the eDA in response to participants' suggestions that this could make the eDA more appealing. Information on combination therapy was moved to the FAQ 'Will this work', as participants had trouble locating that information on the DA. Following the second stage of interviews, we changed information on the availability of treatment via initiatives offered by employers. Participants had misinterpreted this information as an instruction to inform their employer about their depression, whereas the original intended meaning was that their employer may offer free access to therapy 
Table 1 Participant characteristics by interview stage of eDA development

\begin{tabular}{|c|c|c|c|c|c|}
\hline \multirow[b]{3}{*}{ Demographics* } & \multicolumn{2}{|l|}{ Stage 1† } & \multicolumn{2}{|l|}{ Stage 2† } & \multirow{2}{*}{$\begin{array}{l}\text { Stage } 3 \\
\text { Clinicians }\end{array}$} \\
\hline & Patients $\ddagger$ & Public§ & Patients & Public & \\
\hline & $n=5$ & $n=8$ & $n=7$ & $n=8$ & $n=9$ \\
\hline Male & 1 & 3 & 1 & 3 & 6 \\
\hline Female & 4 & 5 & 6 & 5 & 3 \\
\hline $18-44$ & 5 & 3 & 5 & 6 & 1 \\
\hline $45-64$ & - & 3 & 1 & 1 & 8 \\
\hline$>65$ & - & 1 & 1 & - & - \\
\hline
\end{tabular}

Education

\begin{tabular}{|c|c|c|c|c|c|}
\hline Postgraduate & 4 & 1 & 3 & - & 9 \\
\hline Bachelors & - & - & 1 & - & - \\
\hline Associates & - & 2 & 1 & 1 & - \\
\hline High school & - & 3 & 1 & 6 & - \\
\hline \multicolumn{6}{|l|}{ Paid employment } \\
\hline No & 2 & - & 2 & 1 & - \\
\hline
\end{tabular}

*One participant self-identified ethnicity as Hispanic and one participant self-identified as black. All other patients self-identified as White and non-Hispanic.

†Two participants did not report age or employment.

$\ddagger$ Patients self-identified as currently or previously experiencing depression.

$\S O n e$ participant did not report education.

eDA, encounter-based decision aid.

through a benefit scheme. To address this, we changed the language and moved this information to FAQ 'Is there anything else I can do'.

\section{Stage 3: Clinicians}

Nine clinicians were interviewed during the third stage: six family medicine physicians, two general internal medicine physicians and one psychologist. Five of the clinicians completed their professional training more than 20 years ago, two completed training in the past $10-20$ years and two completed training less than 10 years ago. All clinicians worked in primary care and had counselled, diagnosed or treated patients with depression in the past 12 months. Patients with depression represented a majority of the patients seen for seven of the clinicians, a substantial portion for one clinician and a small portion for another clinician.

\section{Overall impression}

Overall, clinicians felt the eDA for depression was visually appealing, comprehensive and helpful. Clinicians indicated that they would either certainly use the DA or consider using the DA. A majority of clinicians $(n=5)$ indicated that the best time to use the DA would be during the visit, introduced by the provider. Several clinicians $(n=4)$ raised concerns about the health literacy level needed to use the eDA for depression.

\section{Suggested changes}

Several clinicians indicated that talk therapy can occur less frequently than weekly and for a shorter amount of time in primary care. We edited the description to reflect this variation. We changed the image of a person on a couch talking to a therapist in a chair, to an image of two people in chairs, based on feedback from one clinician who indicated that the 'picture of someone on the couch could be off-putting to some people' and that newer models of talk therapy are 'more collaborative'. The term 'evidence-based program' was deemed confusing, and it was unclear whether the Internet-based talk therapy program 'Beating the Blues US' was free to use. We simplified the language and provided an example of a free-to-use talk therapy program (MoodGym). Clinicians suggested removing specific cost estimates and medication names. However, this information was important to the general public and patients, and was left unchanged (figure 2).

\section{Part 2. eDA pilot testing}

Participants

Four primary care clinicians and four MAs consented to take part in the study. Of 59 patients approached in both the preintervention and postintervention phases, none declined to participate, three were not eligible to 


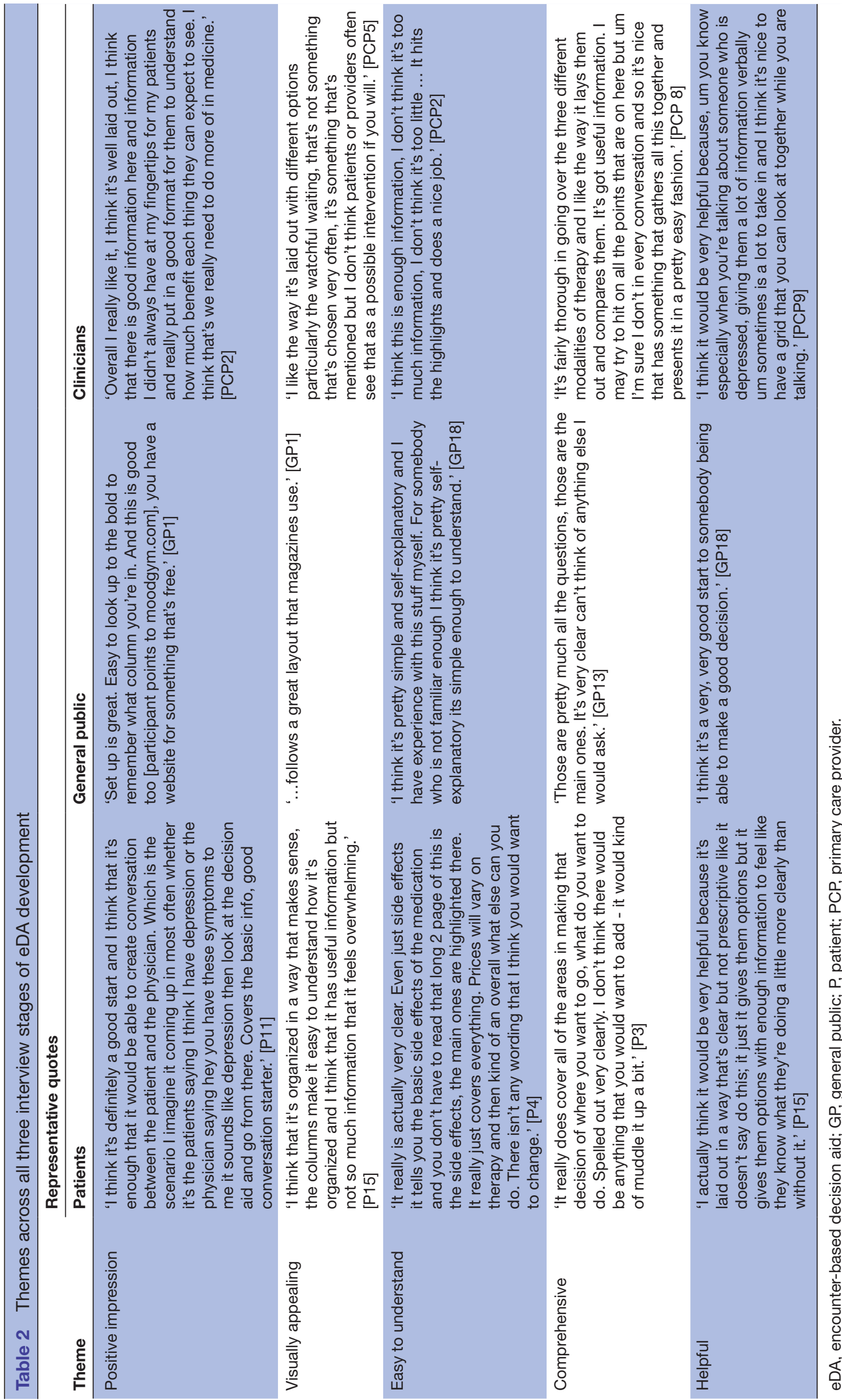




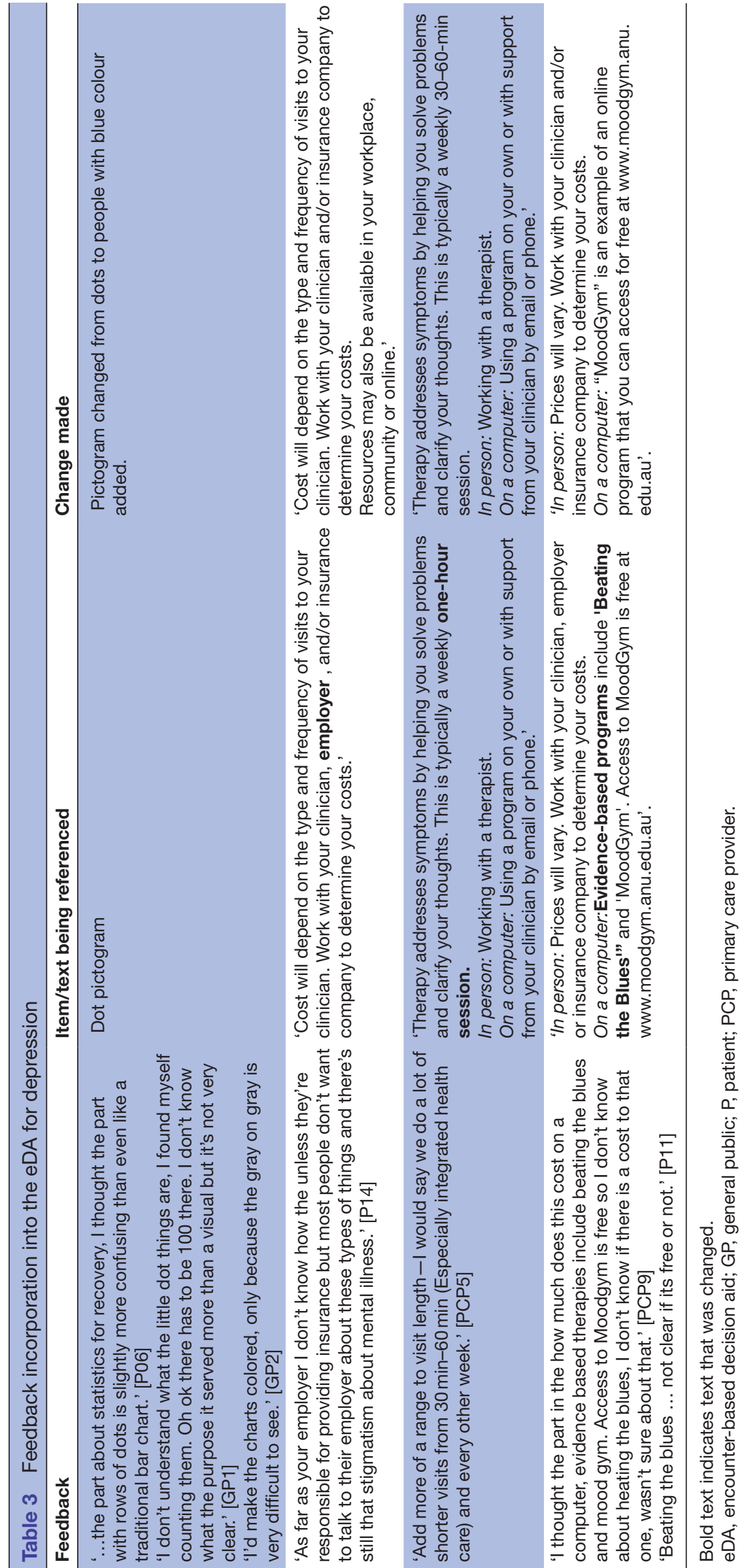


Below are common ways of treating depression in adults. Most people will recover from an episode of depression, however the first treatment may not work and depression may reoccur. It is okay to revisit a treatment decision at any time.

\begin{tabular}{|c|c|c|c|}
\hline $\begin{array}{l}\text { TREATMENTS } \Rightarrow \\
\text { QUESTIONS } \downarrow\end{array}$ & Watchful waiting & Talk therapy & 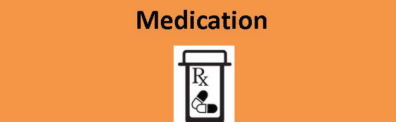 \\
\hline $\begin{array}{l}\text { How does this } \\
\text { work? }\end{array}$ & $\begin{array}{l}\text { This means no active } \\
\text { treatment; you may visit your } \\
\text { clinician more frequently to } \\
\text { monitor your symptoms, } \\
\text { compare options and discuss } \\
\text { your lifestyle, current support } \\
\text { and coping strategies. }\end{array}$ & $\begin{array}{l}\text { Therapy addresses symptoms by } \\
\text { helping you solve problems and } \\
\text { clarify your thoughts. This is typically } \\
\text { a weekly } 30-60 \text { minute session. } \\
\text { In person: Working with a therapist. } \\
\text { On a computer: Using a program on } \\
\text { your own or with support from your } \\
\text { clinician by email or phone. }\end{array}$ & $\begin{array}{l}\text { Selective Serotonin Reuptake Inhibitors } \\
\text { (SSRIs) are medications that address } \\
\text { symptoms by affecting your brain } \\
\text { chemistry. These pills are usually taken } \\
\text { once a day. }\end{array}$ \\
\hline \multirow[t]{2}{*}{ Will this work? } & \multirow[t]{2}{*}{$\begin{array}{l}23 \text { out of } 100 \text { people recover in } \\
3 \text { months by visiting a clinician } \\
\text { without receiving an active } \\
\text { treatment. } 53 \text { out of } 100 \\
\text { people recover in a year } \\
\text { without receiving an active } \\
\text { treatment. }\end{array}$} & $\begin{array}{l}\text { In addition to the } 23 \text { people who } \\
\text { recover without treatment, another } \\
14 \text { out of } 100 \text { people recover in } 2 \\
\text { months by using talk therapy. } \\
\text { Treatment usually lasts } 8 \text { to } 10 \\
\text { weeks, but can last longer. Computer } \\
\text { programs are more effective with } \\
\text { regular clinic check-ins. }\end{array}$ & $\begin{array}{l}\text { In addition to the } 23 \text { people who recover } \\
\text { without treatment, another } 17 \text { out of } \\
100 \text { people recover in } 1 \text { month by using } \\
\text { SSRI medication. Treatment usually lasts } \\
6 \text { to } 12 \text { months. You should talk to your } \\
\text { clinician if you are thinking about } \\
\text { stopping medication. }\end{array}$ \\
\hline & & $\begin{array}{l}\text { In addition to the } 23 \text { people who recov } \\
\text { people recover with a combination of } S\end{array}$ & $\begin{array}{l}\text { er without treatment, another } 26 \text { in } 100 \\
\text { SRIs and talk therapy. }\end{array}$ \\
\hline $\begin{array}{l}\text { What are the } \\
\text { risks? }\end{array}$ & $\begin{array}{l}\text { The risks of watchful waiting } \\
\text { are that your symptoms may } \\
\text { continue or get worse. }\end{array}$ & $\begin{array}{l}\text { The risks of talk therapy are that it } \\
\text { can cause discomfort, anxiety, and/or } \\
\text { stress. }\end{array}$ & $\begin{array}{l}\text { The risks of medication are that it can } \\
\text { cause side effects like nausea, diarrhea, } \\
\text { and drowsiness, which affect up to } 17 \text { in } \\
\text { 100. Sexual problems affect up to } 13 \text { in } \\
\text { 100. Sweating, shaking, difficulty } \\
\text { sleeping, and dry mouth are less } \\
\text { common. }\end{array}$ \\
\hline $\begin{array}{l}\text { How much does } \\
\text { this cost? }\end{array}$ & $\begin{array}{l}\text { Cost will depend on the type } \\
\text { and frequency of visits to your } \\
\text { clinician. Work with your } \\
\text { clinician and/or insurance } \\
\text { company to determine your } \\
\text { costs. }\end{array}$ & $\begin{array}{l}\text { In person: Prices will vary. Work with } \\
\text { your clinician and/or insurance } \\
\text { company to determine your costs. } \\
\text { On a computer: "MoodGym" is an } \\
\text { example of an online program that } \\
\text { you can access for free at } \\
\text { www.moodgym.anu.edu.au }\end{array}$ & $\begin{array}{l}\text { Without insurance, prices vary by } \\
\text { pharmacy. In general fluoxetine, } \\
\text { citalopram, and paroxetine cost less than } \\
\$ 5 \text { for a } 30 \text {-day supply. Sertraline usually } \\
\text { costs less than } \$ 40 \text { and escitalopram less } \\
\text { than } \$ 130 \text { for a } 30 \text {-day supply. } \\
\text { With insurance, prices vary by plans. }\end{array}$ \\
\hline $\begin{array}{l}\text { Is there anything } \\
\text { else I can do? }\end{array}$ & \multicolumn{3}{|c|}{$\begin{array}{l}\text { Resources may also be available in your workplace, community, or online } \\
\text { Exercise, healthy eating, and visiting with friends can reduce symptoms. }\end{array}$} \\
\hline
\end{tabular}

Figure 2 eDA for depression (V.2) used for pilot testing. eDA, encounter-based decision aid.

participate and 56 patients participated. A total of 19 patients in the preintervention phase and 10 patients in the postintervention phase participated in a follow-up interview; 30 patients could not be reached for interview at follow-up. Patients in both phases were predominantly white and female (table 4).

\section{Feasibility, fidelity of eDA use and acceptability}

All patients in the eDA phase (10 of 10 patients) reported receiving the eDA prior to the visit with their clinician. Half of all patients ( 5 of 10 patients) said they read the eDA before talking to their clinician, and 6 of 10 patients reported using the eDA with their clinician during the visit.

Treatment knowledge, assessed only in the eDA phase, was high. All patients (10 of 10 patients) recognised that medication, talk therapy and watchful waiting each have some effectiveness and that episodes of depression can be treated by combining more than one therapy. Five of the six patients who used the eDA and one of the four patients who did not use the eDA correctly reported that talk therapy has fewer risks than medication, that talk therapy is freely available online and that about the same proportion of people will get better with medication as 
Table 4 Patient demographic characteristics by study phase

\begin{tabular}{llc}
\hline & Preintervention & Postintervention \\
\hline $\begin{array}{l}\text { Total number of } \\
\text { participants }\end{array}$ & 19 & 10 \\
\hline Female & 15 & 8 \\
\hline Mean age (SD) & $34.8(15.1)$ & $34.6(14.7)$ \\
\hline Education & & \\
\hline High school or less & 7 & 2 \\
\hline More than high school & 12 & 8 \\
\hline Race and ethnicity & & \\
\hline White & 18 & 9 \\
\hline Asian & - & 1 \\
\hline Hispanic & 2 & 3 \\
\hline Other & 2 & - \\
\hline
\end{tabular}

${ }^{*}$ Multiple responses allowed.

with talk therapy. All of the patients who used the eDA $(6 / 6)$ and half of the patients who did not use the eDA $(2 / 4)$ correctly identified watchful waiting as an effective treatment choice that some people make.

Small sample sizes in both preintervention and postintervention phases render results inconclusive. We did not find evidence for an effect of the eDA for depression on SDM. No difference was found in SDM-Q-9 scores (Wilcoxon rank-sum $\mathrm{z}=-0.259, \mathrm{p}=0.7954$ ) or in CollaboRATE scores (Fisher's exact $\mathrm{p}=0.628$ ) between the study phases. We did find a wider range of treatments selected in the eDA for depression phase, with talk therapy and watchful waiting making up a greater proportion of treatments selected compared with the preintervention phase (table 5).
Debrief interviews

\section{Clinician and MA interviews}

Three of the four clinicians reported a positive experience of using the eDA for depression, highlighting how their discussion of treatment options became more structured with no perceived increase in encounter duration. While one clinician (C03) felt 'neutral' toward the eDA for depression, another stated that the tool 'made me a better clinician' (C01). Two of the clinicians reported that the tool changed their practice by helping them to include more options for patients. When probed further, clinicians revealed that they did not use the tool as had been suggested, often using it as a summary of the discussion that they had with the patient. One clinician stated that they would 'walk through' the tool 'in my mind' when making treatment decisions with patients (C01). Another clinician stated that they would use the tool, 'to strengthen their own recommendations' (C02), the antithesis of its intended use. There was some concern among clinicians and MAs staff that the eDA for depression was 'wordy' (C03) and the font size was too small.

Both clinicians and MAs reported that patients were receptive to inclusion in the project and found the tool 'easy to follow' (MA4) and visually appealing. One clinician was concerned that patients may be 'confused' (C02) if given the eDA based on a PHQ-9 score. This concern was not confirmed by the MAs who recruited patients, introduced and explained the purpose of the eDA. MAs did report confusion over inclusion criteria, excluding patients who were repeat visitors, were receiving medication (whether from the primary care doctor or not) or receiving all the options already offered on the eDA for depression.

Table 5 Outcome measures by study phase of eDA pilot testing

\begin{tabular}{|c|c|c|}
\hline & Predecision aid phase, $n=14$ & Decision aid (eDA) phase, $n=10$ \\
\hline \multicolumn{3}{|l|}{ Shared decision-making } \\
\hline $\begin{array}{l}\text { CollaboRATE: number of patients giving the highest } \\
\text { possible rating }\end{array}$ & 6 & 3 \\
\hline SDM-Q-9: mean score out of 100 (SD) & $80.8(18.1)$ & $78.3(18.8)$ \\
\hline \multicolumn{3}{|l|}{ Number of participants choosing* } \\
\hline Talk therapy & 1 & 4 \\
\hline Watchful waiting & 0 & 1 \\
\hline No treatment $\dagger$ & 0 & 1 \\
\hline \multicolumn{3}{|l|}{ Other: } \\
\hline Seeing a psychiatrist & 1 & 0 \\
\hline
\end{tabular}

*Multiple responses allowed.

†Patient reported that they did not decide on a treatment.

eDA, encounter-based decision aid. 


\section{Patient interviews}

Patients who used the eDA for depression reported that the DA was 'simple and easy to use' (P2) and liked that the tool presented an 'overview' (P7) of all options and used percentages. One patient was concerned that it used 'lots of words' (P1), another felt it was not 'easy to understand' (P7), while another patient wanted more information on insurance coverage and where to access counselling services.

\section{DISCUSSION}

Through a rigorous process, including a series of cognitive interviews, we developed an easy to understand, visually appealing and comprehensive eDA for depression. While clinicians raised concerns about health literacy levels, this was not shared by the general public or patients. Pilot testing of the eDA revealed it could be implemented into the primary care workflow and was generally accepted and well understood. However, the clinicians did not always use the eDA as intended, one clinician used it to reinforce their own recommendations, and there was high attrition during follow-up data collection. There was a greater uptake of talk therapy in the intervention group and no change in SDM. However, the focus of the pilot was on the feasibility of eDA implementation and as such, it was not powered to detect statistically significant differences. We gathered preliminary data on these outcomes (treatment knowledge and SDM) as means of piloting data collection procedures to inform a rigorous assessment of the eDA for depression in a future study.

\section{Strengths and limitations}

The key strength of this project was the systematic development of an eDA, following the steps of DA development outlined by Coulter et $a t^{24}$ and the Option Grid Collaborative. Our community-based focus, with broad engagement of key stakeholders throughout development, is often absent in DA development. ${ }^{24}$ Our participant population was broadly reflective of different education levels, which we believe will increase accessibility of the eDA for patients of different health literacy levels; however, a limitation of our sample is the low number of older adult participants $(n=2)$, where depression is highly prevalent, and primary care-based psychologists $(n=1)$. In addition, our study team included patient partners who contributed to the study design and interpretation of findings. Patient partners were particularly influential in guiding our recruitment strategy, especially when it came to introducing the eDA for depression to patients based on the results of the PHQ-9 screening assessment. We carefully selected wording that reflected the patient's increased risk for depression, but not a definitive diagnosis. This was broadly accepted by patients, with no reports of anxiety or discomfort.

Limitations included lack of fidelity of eDA use during pilot testing. Despite training, support staff often did not present the eDA for depression to patients as per protocol, and clinicians reported giving the tool to patients as they left, not during the visit. However, clinicians did report that the structure of the tool led to them discuss more treatment options with patients and use the general structure of the eDA for depression from memory. A small sample size during the pilot compounded by attrition of $53 \%(30 / 59)$ of patients at follow-up, impacted the potential usefulness in determining the impact of the eDA on SDM. Feedback from patients and clinic staff revealed that this may be due to patients receiving a phone call from a number that is unknown to them. In-clinic completion of follow-up surveys may have resulted in lower levels of attrition and greater project 'buy-in' from patients.

We did not assess health literacy of participants; however, we did have an adequate sample of individuals with low educational attainment. Although a future project should determine the accessibility of the tool by health literacy levels, recent findings of encounters DAs for patients with cognitive deficits due to severe mental health conditions show that psychiatric patients are capable of using DAs and can benefit from doing so. ${ }^{2526}$

Finally, information in eDAs is purposefully kept brief, in order to facilitate use in the clinic visit. This limits the ability of nuances in clinical evidence being fully described; for example, strength of evidence or variations in treatment effectiveness based on severity. It is important that this eDA is updated as new evidence becomes available, as such we propose following guidelines of the Option Grid Collaborative that includes updating evidence in the eDA every 2 years and including an 'expiration' date on the tool.

The development of the eDA for depression is important as it moves beyond medication treatment comparisons for depression to include watchful waiting and talk therapy (in-person and online). ${ }^{827}$ While our study was not powered to detect differences in outcomes, high knowledge and satisfaction scores in our study are similar to those reported for other $\mathrm{eDAs}^{28}$ and Option Grid DAs for clinical encounters. ${ }^{16}$ However, we noted high SDM scores reported in our study-much higher than those found in previous studies of depression in primary care. ${ }^{6-8}$ While these values are based on a small sample size, the high levels reported may be due to the nature of the project. As it was a pilot, clinicians who believe in the value of SDM may have been more likely to opt into the project than those who are more sceptical.

Fidelity of the use of Option Grid DAs for clinical encounters continues to be suboptimal, as reported in a systematic review of these tools, ${ }^{28}$ which may contribute to low implementation in practice. ${ }^{29}$ In the current project, MAs did not systematically follow the study protocol. Additionally, clinicians used the decision aid to guide their discussion, but not during the consultation as intended. Suggesting that even for motivated clinicians, implementation is challenging and a single training session alone may not be sufficient to achieve high fidelity.

One proposed solution is to automate the delivery of eDAs for clinical encounters directly to patients on 
arrival at the clinic through electronic tablets. ${ }^{30} 31$ eDAs for clinical encounters offer personalisation of treatment options and allow real-time decision support linked to risk assessment, such as the PHQ-9 conducted in primary care waiting rooms across the USA. ${ }^{32}$ We have since completed further testing of this eDA to gather information on functionality and layout of digital version to completed in primary care waiting rooms. ${ }^{33}$ We are currently conducting research on how to adapt the eDA for use online. Further consideration of the use of such tools linked to screening and the potential for overdiagnosis should also be explored. ${ }^{34}$

\section{CONCLUSIONS}

Achieving greater alignment of treatment with patient preferences through a process of SDM in the treatment of depression is a goal of primary care. For the first time, patients and clinicians have a widely accepted tool, developed with key stakeholders, which outlines common first-line approaches to treating depression: the eDA for depression. Creating an electronic encounter-based version of the tool, linked to real-time screening for depression, may improve its fit in clinic.

\author{
Author affiliations \\ ${ }^{1}$ The Dartmouth Institute for Health Policy \& Clinical Practice, Geisel School of \\ Medicine at Dartmouth, Lebanon, New Hampshire, USA \\ ${ }^{2}$ Department of Psychiatry, Geisel School of Medicine at Dartmouth, Hanover, New \\ Hampshire, USA \\ ${ }^{3}$ Behavioral Health and Neurosciences Division, Portland Veterans Affairs Medical \\ Center, Portland, Oregon, USA \\ ${ }^{4}$ Department of Psychiatry, Oregon Health \& Science University School of Medicine, \\ Portland, Oregon, USA \\ ${ }^{5}$ The Department of Rehabilitation Sciences, College of Public Health, Temple \\ University, Philadelphia, Pennsylvania, USA \\ ${ }^{6}$ Patent Partner, Hanover, New Hampshire, USA \\ ${ }^{7}$ Patient Partner, Piermont, New York, USA \\ ${ }^{8}$ Departments of Psychiatry and Community and Family Medicine, Geisel School of \\ Medicine at Dartmouth, Hanover, New Hampshire, USA
}

Acknowledgements We would like to thank Dr Magenta Simmons and Dr Pim Cuijpers for their feedback during the content development stage of the eDA development. We would also like to thank Patti Laliberte, clinicians and medical assistants for their support in data collection.

Contributors PJB conceived the study idea. PJB, RCF, MDD, MB, GE, JM, MH, YZ-I and MM contributed to the study design of the cognitive interviews. ET provided clinical expertise on data in the decision aid. PJB, RCF, MDD, MB, GE, JM, MH, YZ-I and MM contributed to the study design of the pilot study. RCF and MDD completed data collection. PJB, RCF and MDD completed the data analysis. PJB, MDD and RCF drafted the initial manuscript. All authors read, revised and approved the final manuscript.

Funding The authors have not declared a specific grant for this research from any funding agency in the public, commercial or not-for-profit sectors.

Competing interests GE has edited and published books that provide royalties on sales by the publishers: the books include Shared Decision Making (Oxford University Press) and Groups (Radcliffe Press). He has in the past provided consultancy for organizations, including (1) Emmi Solutions LLC who developed patient decision support tools; (2) National Quality Forum on the certification of decision support tools; (3) Washington State Health Department on the certification of decision support tools and (4) SciMentum LLC, Amsterdam (workshops for shared decision-making). He is currently the Director of \&think LLC, which owns the registered trademark for Option Grids patient decision aids. He provides consultancy in the domain of shared decision-making and patient decision aids to (1) Access Community Health Network, Chicago (Federally Qualified Medical Centers) and (2) EBSCO Health Option Grids patient decision aids. GE's academic interests are focused on shared decision-making and coproduction. He founded the Option Grid Collaborative. He owns the copyright in measures of shared decisionmaking and care integration, namely collaboRATE, integRATE, Observer OPTION-5 and Observer OPTION-12. These measures are freely available for use.

Patient consent for publication Not required.

Ethics approval Cognitive interviews: This study was approved by the Committee for the Protection of Humans Subjects at Dartmouth College (STUDY\# 28607). Pilot: This study was approved by the Committee for the Protection of Humans Subjects at Dartmouth College (STUDY\# 28897).

Provenance and peer review Not commissioned; externally peer reviewed.

Data sharing statement The data sets used and/or analysed during the current study are available from the corresponding author on reasonable request.

Open access This is an open access article distributed in accordance with the Creative Commons Attribution Non Commercial (CC BY-NC 4.0) license, which permits others to distribute, remix, adapt, build upon this work non-commercially, and license their derivative works on different terms, provided the original work is properly cited, appropriate credit is given, any changes made indicated, and the use is non-commercial. See: http://creativecommons.org/licenses/by-nc/4.0/.

\section{REFERENCES}

1. Trangle M, Gursky J, Haight R, et al. Depression in primary care. 2017.

2. Lindhiem O, Bennett CB, Trentacosta CJ, et al. Client preferences affect treatment satisfaction, completion, and clinical outcome: a meta-analysis. Clin Psychol Rev 2014;34:506-17.

3. Moise N, Falzon L, Obi M, et al. Interventions to increase depression treatment initiation in primary care patients: a systematic review. $J$ Gen Intern Med 2018;33:1978-89.

4. Kocsis JH, Leon AC, Markowitz JC, et al. Patient preference as a moderator of outcome for chronic forms of major depressive disorder treated with nefazodone, cognitive behavioral analysis system of psychotherapy, or their combination. J Clin Psychiatry 2009;70:354-61.

5. Lin P, Campbell DG, Chaney EF, et al. The influence of patient preference on depression treatment in primary care. Ann Behav Med 2005;30:164-73.

6. Young HN, Bell RA, Epstein RM, et al. Physicians' shared decision-making behaviors in depression care. Arch Intern Med 2008;168:1404-8.

7. Solberg LI, Crain AL, Rubenstein L, et al. How much shared decision making occurs in usual primary care of depression? J Am Board Fam Med 2014;27:199-208.

8. LeBlanc A, Herrin J, Williams MD, et al. Shared decision making for antidepressants in primary care. JAMA Intern Med 1761;2015:175.

9. Barr PJ, Forcino RC, Mishra M, et al. Competing priorities in treatment decision-making: a US national survey of individuals with depression and clinicians who treat depression. BMJ Open 2016;6:e009585.

10. Siu AL, Bibbins-Domingo K, Grossman DC, et al. Screening for depression in adults. JAMA 2016;315:380.

11. Kato E, Borsky AE, Zuvekas SH, et al. Missed opportunities for depression screening and treatment in the United States. J Am Board Fam Med 2018;31:389-97.

12. Stacey $\mathrm{D}$, Légaré $\mathrm{F}$, Lewis $\mathrm{K}$, et al. Decision aids for people facing health treatment or screening decisions. Cochrane Database Syst Rev 2017;4:CD001431.

13. Zisman-llani $\mathrm{Y}$, Barnett $\mathrm{E}$, Harik J, et al. Expanding the concept of shared decision making for mental health: systematic search and scoping review of interventions. Mental Health Review Journal 2017;22:191-213.

14. Olfson M, Blanco C, Marcus SC. Treatment of adult depression in the United States. JAMA Intern Med 2016;176:1482.

15. Elwyn G, Lloyd A, Joseph-Williams N, et al. Option Grids: shared decision making made easier. Patient Educ Couns 2013;90:207-12.

16. Elwyn G, Pickles T, Edwards A, et al. Supporting shared decision making using an option grid for osteoarthritis of the knee in an interface musculoskeletal clinic: a stepped wedge trial. Patient Educ Couns 2016;99:571-7.

17. Knafl K, Deatrick J, Gallo A, et al. The analysis and interpretation of cognitive interviews for instrument development. Res Nurs Health 2007;30:224-34. 
18. Guest G, Bunce A, Johnson L. How many interviews are enough? An experiment with data saturation and variability. Field methods 2006;18:59-82.

19. Hsieh HF, Shannon SE. Three approaches to qualitative content analysis. Qual Health Res 2005;15:1277-88.

20. Michie S, Johnston M, Abraham C, et al. Making psychological theory useful for implementing evidence based practice: a consensus approach. Qual Saf Health Care 2005;14:26-33.

21. Elwyn G, Barr PJ, Grande SW, et al. Developing CollaboRATE: a fast and frugal patient-reported measure of shared decision making in clinical encounters. Patient Educ Couns 2013;93:102-7.

22. Barr PJ, Thompson R, Walsh T, et al. The psychometric properties of CollaboRATE: a fast and frugal patient-reported measure of the shared decision-making process. J Med Internet Res 2014;16:e2.

23. Kriston L, Scholl I, Hölzel L, et al. The 9-item Shared Decision Making Questionnaire (SDM-Q-9). Development and psychometric properties in a primary care sample. Patient Educ Couns 2010;80:94-9.

24. Coulter A, Stilwell D, Kryworuchko J, et al. A systematic development process for patient decision aids. BMC Med Inform Decis Mak 2013;13:S2.

25. Zisman-llani Y, Shern D, Deegan P, et al. Continue, adjust, or stop antipsychotic medication: developing and user testing an encounter decision aid for people with first-episode and long-term psychosis. BMC Psychiatry 2018;18:18.
26. Drake RE, Cimpean D, Torrey WC. Shared decision making in mental health: prospects for personalized medicine. Dialogues Clin Neurosci 2009;11:455-63.

27. Duncan E, Best C, Hagen S. Shared decision making interventions for people with mental health conditions. Cochrane Database Syst Rev 2010:CD007297.

28. Wyatt KD, Branda ME, Anderson RT, et al. Peering into the black box: a meta-analysis of how clinicians use decision aids during clinical encounters. Implement Sci 2014;9:26.

29. Inselman J, Branda M, Castaneda-Guarderas A, et al. Uptake and documentation of the use of an encounter decision aid in usual practice. Medical Decision Making 2016;36:557-61.

30. Agoritsas T, Heen AF, Brandt L, et al. Decision aids that really promote shared decision making: the pace quickens. $B M J$ 2015;350:97624.

31. Hoffman AS, Volk RJ, Saarimaki A, et al. Delivering patient decision aids on the Internet: definitions, theories, current evidence, and emerging research areas. BMC Med Inform Decis Mak 2013;13:S13.

32. Siu AL, Bibbins-Domingo K, Grossman DC, et al. Screening for depression in adults: US preventive services task force recommendation statement. JAMA 2016;315:380-7.

33. Dannenberg MD, Bienvenida JCM, Bruce ML, et al. End-user views of an electronic encounter decision aid linked to routine depression screening. Patient Educ Couns 2018.

34. Brodersen J, Schwartz LM, Heneghan C, et al. Overdiagnosis: what it is and what it isn't. BMJ Evid Based Med 2018;23:1-3. 